\title{
40 anos da Pós-graduação da EEFE-USP: uma autocrítica
}

http://dx.doi.org/10.11606/1807-55092017000nesp081
Cláudia Lúcia de Moraes FORJAZ*

Umberto Cesar CORRÊA*

Valmor Alberto Augusto TRICOLI*
*Escola de Educação

Física e Esporte,

Universidade de São

Paulo, São Paulo, SP,

Brasil.

\section{Introdução}

O Programa de Pós-Graduação da Escola de Educação Física e Esporte da Universidade de São Paulo (PPGEEFE-USP) foi iniciado com o Curso de Mestrado em Educação Física em 1977. Tratouse de uma empreitada pioneira tendo em vista ter sido o primeiro Programa de Pós-graduação "stricto sensu” da área de Educação Física na América Latina. Sua criaçáo ocorreu num período de importantes acontecimentos como, por exemplo, o "Movimento Disciplinar da Educação Física", iniciado nos Estados Unidos na década de 1960, cujo cerne estava em inserir a Educação Física no contexto universitário e, assim, conferir-lhe o "status" de área acadêmica". A Educação Física passara a ser vista como uma área de formação e intervenção academicamente orientada e como uma área de conhecimento sobre a natureza e o significado do movimento humano em suas várias formas e manifestaçóes.

Inicialmente, o Programa envolvia apenas uma área de concentração denominada Educação Física. Cerca de uma década depois, em 1989, o PPGEEFE-USP teve mais uma atuação pioneira, com a criação do primeiro Curso de Doutorado em Educação Física da América Latina. Nessa época, o Programa se dividiu em duas áreas de concentração: Pedagogia do Movimento Humano com curso de mestrado e Biodinâmica do Movimento Humano com cursos de mestrado e doutorado.

Posteriormente, como consequência das discussóes a respeito da natureza e do significado do movimento humano relativo ao Esporte, como um dos fenômenos culturais, sociais, políticos e econômicos mais marcantes do mundo contemporâneo, em suas dimensôes e implicaçôes evolutivas, biológicas, sociais, culturais e filosóficas, o PPGEEFE-USP se reorganizou e criou, em 2006, a área de concentração Estudos do Esporte em nível de mestrado e o curso de doutorado na área de concentração Pedagogia do Movimento Humano. Essas iniciativas demonstram, mais uma vez, que ao longo de sua evolução o PPGEEFE-USP sempre teve um caráter de pioneirismo.

No Brasil, a Coordenadoria de Aperfeiçoamento de Pessoal de Nível Superior (CAPES) do Ministério da Educação é o órgão federal normativo e avaliativo do sistema de Pós-graduação. Nas avaliações feitas por essa Coordenadoria, o PPGEEFE-USP passou a receber sempre o conceito máximo a partir do biênio 1983/84, destacando-se, a partir de 2007, a obtenção do conceito de excelência internacional, nota 6 e, já no triênio seguinte, o maior conceito possível de excelência internacional, nota 7, mantido até este momento de festividade.

Em resumo, claramente, durante seus 40 anos de existência, o PPGEEFE-USP tem apresentado um histórico de pioneirismo e excelência, o que caracteriza sua essência. Para a manutenção dessa característica, o Programa precisa permanentemente auto avaliar-se, considerando os rumos da Pósgraduação em nível nacional e internacional, os caminhos estabelecidos pela área de Educação Física na CAPES (área 21; que inclui Educação Física, Fisioterapia, Fonoaudiologia e Terapia Ocupacional), além de outras instâncias de excelência científica e acadêmica. É nesse contexto que o presente artigo se insere. Seu objetivo é apresentar as principais reflexóes e ações realizadas ao longo dos últimos anos com vistas à manutenção e consolidação dessas características de pioneirismo e excelência. 


\section{Desenvolvimento}

\section{Educação física e esporte}

Como apontado anteriormente, em 2006, o Programa criou a área de concentração Estudos do Esporte, indo ao encontro da diferenciaçáo entre Educaçáo Física e Esporte como fenômenos socioculturais com necessidades distintas de intervenção e produção de conhecimento. $\mathrm{O}$ entendimento dessa diferenciação já havia resultado, nos anos 90, na criação dos Cursos de Graduação de Bacharelado em Educação Física e Bacharelado em Esporte, além da mudança do próprio nome da instituição, de Escola de Educação Física para Escola de Educação Física e Esporte. No entanto, o nome do Programa (i.e. Programa de Pós-graduação em Educação Física) com apenas uma área de concentração em Estudos do Esporte colocava a área de Esporte em segundo plano, como uma subárea da Educação Física. Assim, em 2013, o Programa passou a ser denominado "Programa de Pós-graduação em Educação Física e Esporte”, reconhecendo ambas as áreas como igualmente importantes.

\section{O desafio das Áreas de Concentração}

A pós-graduação é um sistema dinâmico. Apesar das três áreas de concentração do Programa terem, inicialmente, abarcado as necessidades de produção de conhecimento, com o passar dos anos as características dessa produçáo mudaram, principalmente em razão da renovação do quadro de orientadores. Passou-se a verificar sobreposiçóes de áreas ou mesmo dificuldade em identificar se um conhecimento pertencia a uma ou outra área. De fato, tornou-se incoerente manter uma área de concentração em Estudos do Esporte e outras duas em Biodinâmica do Movimento Humano e Pedagogia do Movimento Humano, uma vez que os temas Esporte, Pedagogia e Biodinâmica já não representavam áreas distintas entre si. $\mathrm{Na}$ época, vários dos orientadores do Programa atuavam em duas ou nas três áreas de concentração do Programa. Além disso, as áreas de Pedagogia do Movimento Humano e Estudos do Esporte tornaram-se enfraquecidas em termos da quantidade de produção esperada de um Programa de excelência.

Esses acontecimentos trouxeram para dentro do Programa uma discussão presente em outros Programas de Pós-graduação da Educação Física e na própria área 21 da CAPES: a separação das subáreas associadas às Ciências Humanas e às Biológicas. Por exemplo, a própria alocação da Educação Física na grande área das Ciências da Saúde na CAPES, a qual é formada por áreas com grande foco biológico, criou e tem criado conflitos, incoerências, desentendimentos e insatisfações dentro da área 21 em razão de uma valorização mais expressiva do conhecimento relacionado à dimensão biológica do ser humano. Entretanto, conforme descrito anteriormente, a Educação Física e o Esporte são áreas do conhecimento extremamente ricas e complexas, em razão de seus objetos de estudo e, consequentemente, intervençáo, necessitarem de abordagens em diferentes níveis de análise, do bioquímico ao sociocultural. O ponto aqui é que os critérios de avaliação dos Programas da área 21 foram, inicialmente, muito focados em critérios com expressiva validade para áreas biológicas e, portanto, com pouca utilização e relevância para as áreas humanas. Esse aspecto teve grande impacto na área de Educação Física, principalmente, para os orientadores de Programas cujo cunho científico se voltava de forma mais evidente às humanidades.

Em suma, esses descontentamentos estimularam, em alguns Programas, a reflexão sobre a separação de suas subáreas em Programas distintos. No PPGEEFE-USP, essa discussão foi bastante acalorada e envolveu grande parte dos docentes orientadores. Surgia a ideia de se separar as áreas de concentração em dois Programas distintos, um voltado à área de Biodinâmica da Educação Física e do Esporte, que continuaria ligado à área 21 da CAPES, e outro voltado à área de Pedagogia da Educação Física e do Esporte, que poderia passar, por exemplo, para a área de Educação da CAPES. Esse momento de discussão e tomada de decisão foi crucial no desenvolvimento do Programa, pois o caminho tomado não apenas afetaria de forma substancial o próprio Programa, mas, certamente, teria impacto sobre a área de Educação Física como um todo.

As discussões, no entanto, amadureceram e passaram para uma posição única, que considerou que a separação e, por conseguinte, transformação das áreas biológicas e de humanidades da Educação Física e do Esporte em Programas distintos, as descaracterizaria, ou melhor, descaracterizaria a Educaçáo Física e o Esporte como fenômenos complexos. Dessa forma, numa decisão, que talvez 
tenha sido uma das mais importantes tomadas pelo Programa ao longo de sua existência, optou-se pela manutenção de um único Programa com distintas áreas de concentração.

O PPGEEFE-USP, então, reestruturou suas áreas de concentração de modo a abranger as produçóes de conhecimentos. Quais sejam:

- "Estudos Biodinâmicos da Educação Física e Esporte”, que envolve o estudo da Educação Física e do Esporte a partir das perspectivas biofísica, bioquímica e biológica;

- "Estudos Socioculturais e Comportamentais da Educação Física e Esporte”, que envolve o estudo da Educação Física e do Esporte a partir das perspectivas comportamental e sociocultural.

\section{A formação acadêmica do discente - estrutura curricular e ações para a excelência}

É importante lembrar que, mais do que um sistema de produção de conhecimentos, a pósgraduação é um sistema de ensino e formação de recursos humanos. Assim, baseado nos preceitos de excelência da pós-graduação da Universidade de São Paulo, os quais afirmam que "A pós-graduação stricto sensu, voltada à geração de conhecimento, destina-se à formação de docentes, pesquisadores e profissionais com amplo domínio de seu campo do saber e capacidade de liderança e inovaçáo" ${ }^{2}$, o PPGEEFEUSP definiu o perfil do egresso desejado, que abrange a formação de docentes, pesquisadores e profissionais com domínio do conhecimento e capacidades de comunicação, supervisão, liderança e produção de conhecimento em Educação Física e Esporte. Essa concepção destaca alguns pontos cruciais que devem ser visados na formação do discente: conhecimento inovador, liderança e comunicação.

Considerando-se o domínio e a produção de conhecimento inovador, para a obtenção de habilidades necessárias para se atingir a excelência, o PPGEEFE-USP entendeu ser necessário desenvolver nos alunos não apenas conhecimentos específicos de seu projeto de pesquisa, mas também estimulá-los à obtenção de conhecimentos amplos sobre Ciência, sobre a área de Educação Física e Esporte e sobre outros aspectos da área de investigação escolhida para o projeto específico. Para atingir esses objetivos, na reformulação da estrutura acadêmica do Programa, foi instituída uma grade curricular caracterizada por um sistema com complementaridade entre regras fixas e estratégias flexíveis ${ }^{3}$.
Dessa forma, a estrutura curricular foi organizada em quatro níveis. $\mathrm{O}$ primeiro diz respeito àquele mais macroscópico, no qual o aluno é "obrigado" a cursar disciplinas que abordem conteúdos fundamentais à formação científica em qualquer área, por serem a base da formação acadêmica em nível de pós-graduação. Esses conteúdos são: filosofia da ciência, metodologia da pesquisa e estatística. O segundo nível remete-se à abordagem de temáticas pertinentes ao contexto da Educação Física e do Esporte, no qual são oferecidas disciplinas na forma de Seminários em: Educação Física e Esporte, Estudos do Esporte, Pedagogia do Movimento Humano e Biodinâmica do Movimento Humano. $\mathrm{O}$ terceiro nível diz respeito àquele com disciplinas específicas às linhas de investigação, que são agrupadas dentro de cada área de concentração e se complementam com disciplinas comuns às duas áreas. Por fim, no quarto nível, a preocupação está em oferecer ao aluno conhecimentos e capacidades relativas à dimensão de docência, sendo esse nível atrelado ao Programa de Aperfeiçoamento de Ensino (PAE) da USP, que possibilita ao aluno a experiência prática na didática do ensino superior ao acompanhar um professor numa disciplina de graduação. É importante destacar ainda que o aluno pode fazer as disciplinas que váo compor seu plano de estudo (elaborado em conjunto com seu orientador) no próprio Programa, em outros programas da Universidade de São Paulo ou ainda em outras Universidades, o que confere importante flexibilidade à grade e responsabilidade ao aluno sobre sua própria formação.

Considerando-se as capacidades de liderança e comunicação dos discentes, o PPGEEFE-USP estimula o desenvolvimento dessas capacidades através do incentivo à execução de atividades extracurriculares, como participação em congressos, visitas a laboratórios, escrita de artigos e intercâmbios no exterior, que podem ser creditados em seus históricos escolares. Além disso, as normas estabelecidas no início do quadriênio incluíram uma importante modificação no exame de qualificação, no qual o aluno deve apresentar seu projeto (escrito e oral), fazer uma explanação oral sobre um tema da sua linha de investigação, apresentar seu relatório de atividades desenvolvidas no período do curso e responder às arguiçóes da banca. As diversas etapas desse exame visam analisar a evolução do aluno nos aspectos fundamentais abordados anteriormente, ou seja, conhecimento geral, conhecimento específico e capacidade de liderança, comunicação e inovação, 
avaliando sua maturidade acadêmica em coerência com o nível de formação (mestrado ou doutorado) e com os objetivos de um Programa de excelência.

Duas considerações em relação a alguns aspectos práticos vigentes na área na época da elaboração dessas normas talvez sejam pertinentes de serem destacadas. Primeiro, a atitude do Programa incluindo uma formaçáo ampla remou contrariamente à maré imposta na época de supervalorização da produção de artigos e de "inchaço" do Currículo Lattes. Nesse sentido, embora o PPGEEFE-USP sempre tenha entendido ser fundamental a difusão do conhecimento produzido em revistas científicas de elevada qualidade, ele considera essa produção como consequência de uma boa formação e da produção de conhecimento relevante e inovador, não sendo adequada a publicaçáo de dados inacabados apenas para cumprir exigências. Por esse motivo, as normas do Programa não incluíram a produção de artigos como obrigatória para a finalizaçáo do curso, embora tenham informado a necessidade da divulgação do conhecimento.

Em segundo lugar, a proposta apresentada de ampliação do conhecimento oferecido e exigido para além do conhecimento específico do projeto de pesquisa foi de encontro a uma crítica comum presente em diversos concursos públicos, onde vários candidatos formados no doutorado e com alta produção de artigos publicados, não eram aprovados em provas teóricas sobre conhecimentos gerais da área. O PPGEFEE-USP entendeu que a formação mais global e profunda, com ênfase em aspectos teóricos e práticos de diversos níveis, prepara de forma mais adequada o aluno para a atuação profissional futura em diferentes áreas.

\section{A excelência do corpo docente}

Obviamente, qualquer Programa de Pósgraduação de excelência depende também de um corpo docente de excelência e do apoio à evolução desse corpo docente. Nesse sentido, as normas do PPGEEFE-USP para o credenciamento e recredenciamento de orientadores sempre visou estabelecer diretrizes sobre as qualidades esperadas. As normas do Programa consideraram que as exigências para a excelência deveriam ser coerentes com o nível de credenciamento (mestrado e/ou doutorado) e também em termos de credenciamento ou recredenciamento no mesmo nível. Além disso, discriminou-se nas normas as diretrizes de atuaçáo na pós-graduação, incluindo não só a excelência na produção científica, mas também a atuação didática e, no caso de recredenciamento, as metas de formaçáo de recursos humanos.

Considerando-se a produção intelectual de excelência, deve ser destacado que os conceitos e a compreensão sobre essa excelência foram mudando ao longo da evolução da Pós-graduação em Educação Física no Brasil. Na década de 1990, a produçáo de artigos na área de Educaçáo Física era muito pequena ${ }^{4-5}$, e a meta naquela época era fazer com que os docentes ligados aos Programas de Pós-graduação tivessem alguma publicação científica. Ao longo dos anos, essa meta se modificou para o aumento da quantidade de publicaçóes. Mais recentemente, passou-se a enfatizar a maior qualidade e, atualmente, alguma preocupação tem sido levantada sobre a produção com participaçáo real da díade docente/discente diretamente derivada do Programa. Na área 21 da CAPES, essas modificaçóes se expressaram ao longo do tempo na modificação dos critérios de avaliação, com a inclusão de pontuação para a produção de artigos, a qualificação das revistas pelo Qualis e a inclusão de critérios específicos para a quantificação de artigos publicados em revistas de estratos de maior qualidade $^{6}$. E, mais recentemente, a inclusão de pontuação diferenciada para a produção com o discente ou egresso do Programa.

No PPGEEFE-USP, essas mudanças conceituais de excelência de produção intelectual também tiveram impacto e influenciaram as decisóes em relação às exigências para o credenciamento e recredenciamento de docentes. Entretanto, é importante destacar que a excelência da produção científica não é determinada exclusivamente pelos conceitos da CAPES. De fato, outros órgãos de fomento e gestâo da pesquisa, nacionais e internacionais, também influenciam o conceito de excelência e, em vários momentos, os critérios usados para avaliar a excelência podem não ser semelhantes ou mesmo ser conflitantes entre esses órgãos. Nesse sentido, para o PPGEEFE-USP e seus docentes, algumas pressóes, nem sempre sinérgicas, foram importantes para determinar o conceito de excelência, como: a) a visão de Pós-graduação da própria Universidade, expressa pelos posicionamentos da Pró-Reitoria de Pós-graduação; b) a visão de excelência científica do Conselho Nacional de Desenvolvimento Científico e Tecnológico (CNPq) e da Fundaçáo de Amparo à Pesquisa do Estado de São Paulo (FAPESP), principais financiadores das pesquisa do corpo docente do Programa; e c) a expectativa de excelência 
intelectual de órgãos internacionais de fomento, que são objetivo da internacionalização de um Programa nível 7. Além disso, por se tratar de um Programa líder, essa excelência também precisa ser pensada e refletida em relação ao entendimento do corpo docente do próprio Programa.

Diante desse complexo quadro de decisão sobre a excelência da produção intelectual, os critérios de credenciamento e recredenciamento dos docentes do Programa são constantemente analisados e não refletem exclusivamente as solicitaçóes da CAPES. De fato, em alguns momentos eles concordam com a CAPES, em outros antecedem as decisões da CAPES, às vezes possuem critérios extras à CAPES e, pontualmente, podem apresentar aspectos contrários às decisões da CAPES. O Programa já incluía para o credenciamento de docentes a necessidade de publicaçóes em revistas de qualidade, expressas como revistas classificadas como A1 e A2 no Qualis. Contudo, por entender a importância da liderança de nossos docentes na produção científica que possuem, estipulamos uma produçáo mínima "como primeiro ou último autor". Para finalizar, por não concordar com os critérios vigentes de avaliação da qualidade da produção intelectual na forma de livros e capítulos de livros, o Programa passou a utilizar um sistema de pontuação sem nenhuma relação com aquela utilizada pela CAPES. Nesse sentido, o Programa adotou um sistema simplificado de avaliaçáo considerando três aspectos: 1. autor ou editor/organizador; 2. livro ou capítulo; e 3. nível de circulação. O termo circulação não foi aplicado no sentido comercial de acessibilidade (encontrar-se à venda em livrarias do mundo), mas no sentido acadêmico de acessibilidade e, portanto, ser publicado em idioma que permite maior acessibilidade à obra.

Talvez o posicionamento do PPGEEFE-USP em relação à excelência da produção intelectual seja um ponto crucial para o Programa, pois ele náo segue direta e cegamente nenhuma das instâncias de avaliação anteriormente citadas (CAPES, CNPq, FAPESP, PróReitoria, entre outras), demonstrando sua autonomia e capacidade de decisão e liderança, o que têm permitido a manutenção da excelência nessas diversas instâncias.

\section{O empreendimento \\ e as repercussões da internacionalização}

Conforme colocado anteriormente, aos olhos da CAPES a excelência de um Programa depende de seu grau de internacionalização. Em geral, a internacionalização em Educação Física e Esporte é incipiente no que diz respeito à produçáo do conhecimento, principalmente quando se compara com áreas mais tradicionais. Porém, é importante destacar que a internacionalização é um processo complexo, isto é, que envolve vários componentes, e se faz com base em políticas e açôes, cujos resultados são obtidos em médio e longo prazos. O PPGEEFEUSP intensificou suas ações de internacionalização nos últimos 10 anos, após a obtenção da nota 6 . Um facilitador desse processo foi recepção de verba do Programa de Excelência da CAPES (PROEX) e a autonomia para geri-la com editais específicos de incentivo à internacionalização.

Os investimentos de internacionalização do Programa em relação às açóes docentes envolveram: a) financiamento de estágios ou visitas a laboratórios no exterior, visando o estabelecimento de parcerias científicas internacionais; b) recepção de pesquisadores de renome internacional no Programa; c) participação de professores estrangeiros em bancas do Programa; d) organização de eventos internacionais; e e) pagamento de publicaçóes em periódicos de circulação internacional.

Considerando-se as açóes discentes, pode-se citar: a) visitas a universidades estrangeiras;b) incentivo a apresentaçáo de trabalho em congressos no exterior; c) execução de estágios de doutorado sanduíche em laboratórios internacionais; e d) participação de pós-doutorandos em estágios no exterior.

Quanto às açóes institucionais, elas envolveram: a) a tentativa de estabelecimento de um convênio de dupla titulação com a Universidade do Porto em Portugal; e b) a internacionalização das informaçóes sobre o PPGEEFE-USP no site da Instituiçâao, com todas as informaçóes disponíveis em inglês e espanhol.

\section{A solidariedade do Programa}

$\mathrm{Na}$ visão atual da Pós-graduação, a excelência implica não apenas em ações visando o progresso específico do Programa, mas sua atuação contribuindo para a melhoria da formação de recursos humanos e da produção de conhecimento da área, bem como para a melhora da sociedade em geral. Nesse sentido, desde sua criação, o Programa sempre desenvolveu uma série de açóes, que podem ser consideradas como de Solidariedade. Essas açôes envolvem atividades institucionais e individuais, com amplitude nacional e internacional.

Considerando-se as atividades de solidariedade internacional, um ponto de destaque é o convênio que o Programa mantém, há vários anos, com a Universidade 
Pedagógica de Moçambique. Essa ação implica no acompanhamento da evolução desse programa, na assessoria acadêmica e na contribuição em várias etapas, incluindo a ministração de disciplinas, orientação de alunos e produçáo conjunta de conhecimento. Em relação a outras solidariedades oficiais e institucionais, embora o PPGEEFE-USP tenha buscado ao longo do tempo o estabelecimento de iniciativas como DINTER, MINTER, “CASADINHO”, PROCAD, entre outros, e os tenha desenvolvido em momentos anteriores, sendo até pioneiro nessas açōes, nos últimos anos as dificuldades administrativas e as restrições de financiamento para esses programas impediram sua concretização.

Ainda assim, visando contribuir para a formação de recursos humanos de maior qualidade no país, o PPGEEFE-USP desenvolveu açóes que incluíram a organização e condução de: a) eventos científicos nacionais e internacionais; b) cursos de atualização (difusão e aperfeiçoamento) e de especializaçáo, presenciais e à distância; c) cursos para aprimoramento de alunos de iniciação científica de todo o país; e e) ciclos de conferências relacionadas à Educação Física e Esporte, transmitidos via internet. Considerando-se o aprimoramento nacional da produção do conhecimento na área, os docentes do PPGEEFE-USP estabeleceram parcerias científicas e publicaçóes conjuntas com diferentes instituiçóes de ensino superior de todas as regióes do país.

Além disso, o PPGEEFE-USP desenvolveu açôes relacionadas à Educação Básica, através da ministração de cursos e seminários para a preparação profissional da Educação Física na Escola, bem como fez atuaçóes junto aos órgãos políticos com influência nesse nível educacional. Cumpre destacar que no intuito de ajudar na escolha profissional, o PPGEEFE-USP também desenvolveu atividades de recepção dos alunos do ensino médio e um programa de pré-iniciação científica, que se propóe a estimular o senso científico no aluno do ensino médio.

\section{Considerações finais}

Pelo exposto, observa-se que o PPGEEFE-USP se caracteriza, desde sua criação, há 40 anos, pelo pioneirismo e excelência. A meta das diferentes geraçôes que compuseram esse Programa ao longo de sua existência sempre foi a manutenção dessas características. A análise crítica dos últimos anos
Com relação às ações de solidariedade envolvendo a sociedade em geral, os docentes do PPGEEFEUSP oferecem à comunidade cursos e programas comunitários, envolvendo a prática de atividades física para a melhora da saúde e da qualidade de vida. Destaca-se que essas atividades de extensão universitária envolvem a atuação de discentes, estando relacionadas ao ensino e também vinculadas à produção do conhecimento científico aplicado. Além disso, o PPGEEFE-USP possui vias de comunicação com a sociedade em geral a partir de "blogs" e de entrevistas fornecidas à diferentes meios de comunicação.

\section{Os egressos e seus caminhos}

O acompanhamento das atividades dos egressos é uma importante ferramenta para avaliar a excelência de um programa de pós-graduação. Porém, a obtenção de dados a respeito da atuação de egressos, principalmente em um Programa de longa história, é bastante complexa e tem sido buscada em diferentes instâncias ainda sem resultados adequados.

Considerando-se o PPGEEFE-USP, um ponto importante é a nucleação dos egressos. Nesse sentido, importa destacar que grande parte dos Programas de Pós-graduação da área de Educação Física possui pelo menos um egresso do PPGEEFEUSP em seus quadros docentes. Muitos egressos assumiram funçóes relevantes no sistema de Ciência e Tecnologia do país, assumindo cargos na CAPES, FAPESP, CNPq e outros órgãos gestores. Mesmo os egressos recentes, formados no último quadriênio, têm obtido posiçóes como professores em Universidades de todo o país, são orientadores de programas de Pós-graduação e vários continuaram no sistema como pós-doutorandos. Ressalta-se, no entanto, que um levantamento mais preciso e detalhado da atuação dos egressos se faz necessário para uma avaliação mais precisa. permite observar os esforços do Programa para atingir e manter essas características. Nesse sentido, o PPGEEFE-USP modificou sua estrutura e normas no sentido de se ajustar aos conceitos relacionados às subáreas que o compóe e para garantir o perfil de excelência do egresso. O PPGEEFE-USP 
também tomou atitudes relacionadas à excelência do corpo docente, criando sua concepção própria sobre a mesma, com base na análise crítica de pressóes internas e externas, mas mantendo sua independência. O PPGEEFE-USP preocupouse ainda com os aspectos de internacionalização, visando mostrar no exterior a excelência de sua capacidade de produção de conhecimento e formação de recursos humanos. Para além disso, o PPGEEFE-USP empreendeu ações de solidariedade nacionais e internacionais, visando o desenvolvimento compartilhado com essas instâncias. Em nossa opinião, através dessas ações, o Programa conseguiu, ao longo dos últimos anos, manter o pioneirismo e excelência que o caracteriza desde sua criação. Obviamente, para a manutenção dessas características, o Programa deve continuar a avaliar constantemente sua posição, suas açóes e a repercussão dessas açôes, considerando criticamente as pressóes internas e externas, de modo a tomar decisóes sem perder de vista as características desejadas.

\title{
Referências
}

1. Tani G. Leituras em educação física: retratos de uma jornada. São Paulo: Phorte; 2011.

2. Universidade de São Paulo. Regimento de Pós-Graduação. Resolução 6542, de 18 de abril 2013. São Paulo: USP; 2013. Disponível em: http://www.leginf.usp.br/?resolucao=resolucao-no-6542-de-18-de-abril-de-2013-2.

3. Universidade de São Paulo. Resolução CoPGr 6651 e 6652 de dezembro 2013. Regimento da Comissão de Pós-Graduação da Escola de Educação Física e Esporte e Regulamento do Programa de Pós-Graduação em Educação Física e Esporte da Escola de Educação Física e Esporte. São Paulo: USP; 2013. Disponível em: http://citrus.uspnet.usp.br/eef/uploads/ arquivo/Regimento\%20e\%20regulamento_pg_web.pdf.

4. Kokubun E. Pós-graduação em educação física no Brasil: indicadores objetivos dos desafios e das perspectivas. Rev Bras Ciênc Esporte. 2003;24:9-26.

5. Kokubun E. Pós-graduação em educação física. Rev Bras Educ Fís Esporte. 2006;20:31-3.

6. Tani G. Educação física: por uma política de publicação visando à qualidade dos periódicos. Rev Bras Ciênc Esporte. 2007;29:9-22.

\author{
ENDEREÇO \\ Cláudia Lúcia de Moraes Forjaz \\ Escola de Educação Física e Esporte - USP \\ Av. Prof. Mello Moraes, 65 \\ 05508-030 - São Paulo - SP - BRASIL \\ e-mail: cforjaz@usp.br
}

